\title{
A study of the diversity of natural topography in straight and meandering streams by the installation of groynes
}

\author{
D. H. Choi ${ }^{1}$, G. S. Hwang ${ }^{2}$, S. Y. Kim ${ }^{1}$, D. O. Kim², B. M. Kim², \\ H. S. Song ${ }^{1} \&$ J. H. Park ${ }^{3}$ \\ ${ }^{1}$ University-Industry Cooperation Foundation of Kangwon National \\ University, Korea \\ ${ }^{2}$ Halla Engineering \& Construction Corporation, Korea \\ ${ }^{3}$ Korea Ecosystem Research Institute, Korea
}

\begin{abstract}
This study observed topographic changes resulting from installed groynes at straight and meander experimental test-beds (Shihwa wetland). Bed and edge changes were induced more with installation of groynes than without. In comparison of the installation angle of groynes, erosion was found in the case of $45^{\circ}$ to the stream flow while deposition in the case of $135^{\circ}$. In the case of the installation shape of groynes, various topographic changes were found more with those of double bar type than those of one bar type. After that we applied them to a field test-bed (Geumdang Valley) to conduct a comparative analysis. We observed results of topographic change and biodiversity after more than one year from the installation of groynes at the field test area based on test-bed results. In the real stream, which minimized manmade elements, more forms of bed and edge of stream could be created only with the installation of groynes similar to the results of the test-bed. We observed that various topographic changes could form kinds of habitats of fishes and benthic invertebrates.

Keywords: groyne, topographic change, biodiversity, habitat.
\end{abstract}

\section{Introduction}

Groynes are structures constructed in lowland rivers at an angle to the flow direction in order to deflect the flowing water away from critical zones [1]. They 
serve to redirect flow, protect the riverbank from erosion, create stable pools for aquatic habitat, and trap suspended sediment in backwater zone. A groyne has the function of aquatic life's shelter or habit, and interest in groynes increase from the river and ecosystem restoration perspective [2]. A groyne has advantages such as reducing velocity around the embankment and diversifying river flows through the formation of the recirculation zone, In addition it partially disrupts the flow of a river, thereby influencing riverbed change by increasing velocity around the main channel $[3,4]$.

Aqua Restoration Research Center located in Gifu Prefecture, Japan is studying the variation of channel bed resulting from velocity and rate of artificial flow. By doing so, it applies straight and meander streams` change of channel bed in flood season and biodiversity maintenance function of surround lives to the field [5]. Saint Anthony Falls Lab. (Minnesota Univ.) is studying relationship between various forms of groynes and bed and edge of the water, using 3-D flow as well as sediment transfer analysis equipment on the meander streams.

This study observed topographic changes resulting from installed groynes at straight and meander experimental test-beds. It has done a comparative analysis of bed and edge of streams' quantitative value of topographic changes by using LiDAR (RIEGL VZ-400). After that we applied them to field test-bed to conduct a comparative analysis. Also, we observed the various topographic changes could form kinds of habitats of fishes and benthic invertebrates.

\section{Material and method}

\subsection{Experimental test bed}

\subsubsection{Specification}

The experiments were conducted in the testing field which is in Shihwa Lake Reedy Marsh Park in Ansan, Gyeonggi-do (126 $\left.51^{\prime} \mathrm{N}, 3^{\circ} 15^{\prime} \mathrm{E}\right)$. We made a

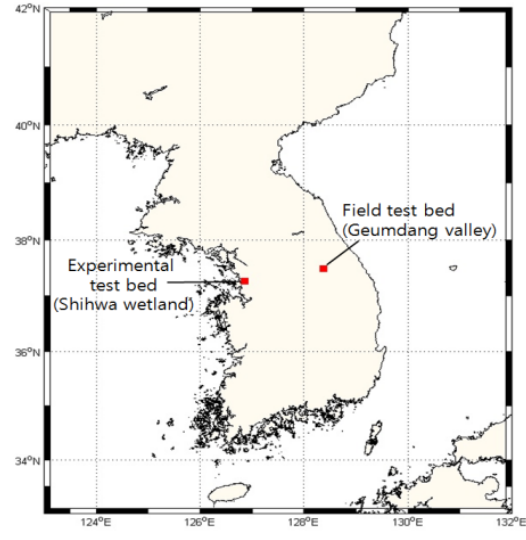

Figure 1: The site map of test bed. Figure 2:

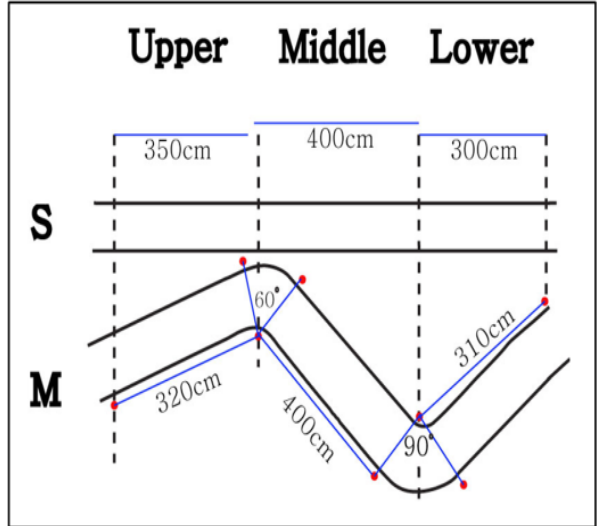

Scale of experimental test bed (S: Straight, M: Meander). 
straight and a meander stream on the experimental test prior to the field test. The straight stream had a $1 \mathrm{~m}$ width channel and consisted of a $17.5 \mathrm{~m}$ length and a $3.3 \mathrm{~m}$ width. The meander stream consisted of a $17.5 \mathrm{~m}$ length and a $7.8 \mathrm{~m}$ width. The channel of the meander stream had a $1 \mathrm{~m}$ width and contained a $60^{\circ}$ upper curve at $3.2 \mathrm{~m}$ point from the beginning of the stream and a $90^{\circ}$ lower curve at $7.2 \mathrm{~m}$ point. These experiments were conducted on a bed consisting of uniform bed material of sand ranging from $0.1 \mathrm{~mm}-0.2 \mathrm{~mm}\left(\mathrm{D}_{50}\right)$. The groynes installed to the stream had sizes of $6 \mathrm{~cm}(\mathrm{~W}) \times 15 \mathrm{~cm}(\mathrm{~L}) \times 5 \mathrm{~cm}(\mathrm{H})$ and types of one bar type (-) or double bar type (=). Also they were made of $2 \sim 3 \mathrm{~cm}$ gravels.

\subsubsection{Methods}

Experiments were taken on conditions of installation angle $\left(45^{\circ}, 135^{\circ}\right)$, intervals of distance (A: 1m, B: $2 \mathrm{~m}$ ) and types (one bar type, double bar type). It used two 7HP pumps that ran water for 10 minutes in order to observe the topographic variation. The studied two cases which are divided into a normal season (1Q) and a flood season (2Q) by giving changes of rate of flow (1Q: 12L/sec, 2Q: 23.5L/sec). It used a hydrometer (Swoffer 2100) for partial velocities and ping pong balls for sectional velocities. After $1 \mathrm{Q}$ and $2 \mathrm{Q}$ experiments, we completely vaporized water in the streambed and took topographic variation data using topographic survey equipment, LiDAR (RIEGL VZ - 400). Subdivided into 3 cases of base (before tests), 1Q (after 1Q test) and 2Q (after 2Q test), the topographic data was obtained.

\subsection{Field test}

\subsubsection{Specification}

\subsubsection{Geumdang valley in Pyeongchang river}

Field test area is Geumdang valley located in Gaesu-ri, Pyeongchang-gun, Gangwon-do $\left(128^{\circ} 23^{\prime} \mathrm{N}, 3^{\circ} 29^{\prime} \mathrm{E}\right)$. It is mountain type stream and its streambed composed of gravels and sand. The annual rainfall in Geumdang valley is concentrated in summer and range of rainfall variation is considerable. Hydraulic characteristic was found that there were simple forms of depositions and erosions are repeating.

The forms of installed groynes are mixture of one bar type and double bar type which were used at the simulation. The groynes consisted of $1.35 \mathrm{~m}(\mathrm{~W}) \times$ $6.00 \mathrm{~m}(\mathrm{~L}) \times 1.80 \mathrm{~m}(\mathrm{H})$ and made of wood. To endure the drag and tractive force against the flow, inside of the groynes were filled with boulders for the high stability.

\subsubsection{Field topography and biogacies investigation}

Fish fauna for evaluation of habitat function was collected for 50 minutes per each station with a skimming net (mesh size $500 \mu \mathrm{m})$. Invertebrate animals were collected by using Surber's net $(30 \times 30$, mesh size $500 \mu \mathrm{m})$, Modified semiquantitative $\mathrm{d}$ - frame deep net (mesh size $500 \mu \mathrm{m}$ ), Hess sampler (mess size $500 \mu \mathrm{m}$ ), Deep net, collector, Hand net, etc. 
Light wave distance measurement (Nikon DTM - 520) was used for topographic variation. Building virtual triangle grids on research area, we applied them to SMS model and forecasted the hydraulic characteristics by using results of light wave measurement. There are RMA-2 model that is based on finite element method and SED2D model in SMS models. On the basis of SMS model, we investigated long-term topographic change by putting virtual seasonal variation of the rate of flow in research area. We predicted it using SED2D model for 12 months (6 months 1Q, 3 months 2Q, 3 months 1Q) and took virtual deposit and erosion value.

\section{Results and discussions}

\subsection{Test bed}

We conducted a comparison analysis of topographic changes from LiDAR sources. For more accurate topographic changes, we subdivided the straight stream into upper, middle and lower parts. Also we subdivided the meander stream into upper, upper curve, middle, lower curve and lower parts. Each section was divided into left bank, bed and right bank. Therefore, we obtained totally nine districts of the straight stream and fifteen districts of the meander stream.

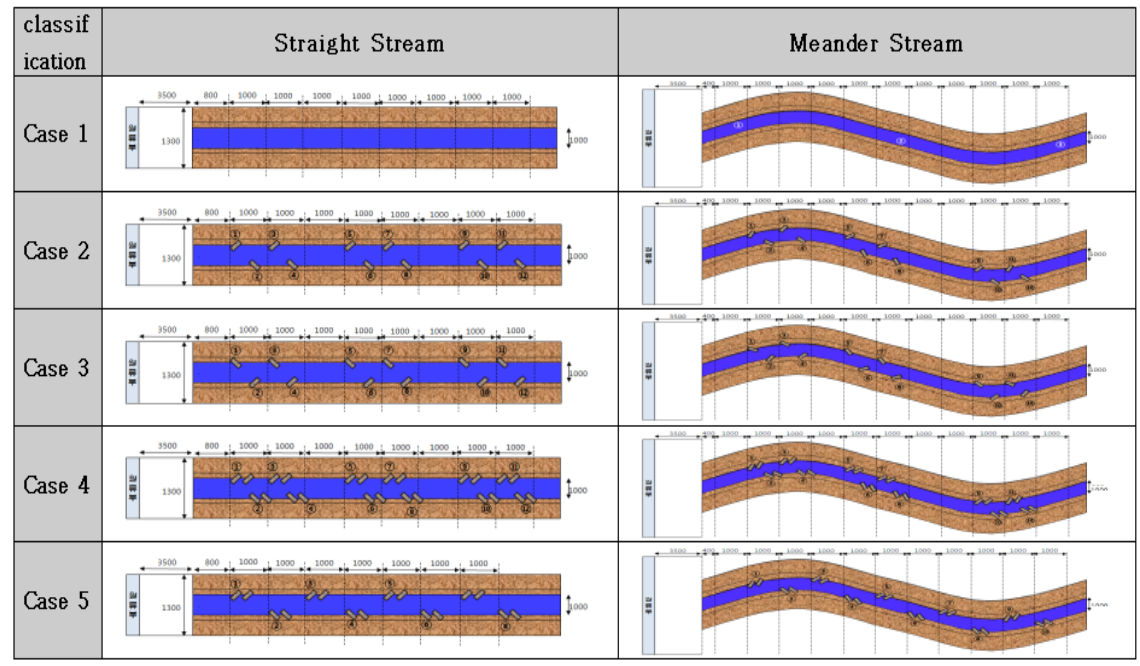

Figure 3: Installation of groynes in straight and meander stream of experimental test bed.

\subsubsection{Experimental conditions}

In the straight and meander streams, Case 1 is a comparison group without an installation of groynes. In Case 2, we installed one bar type groyne $45^{\circ}$ to the stream flow, at intervals of $1 \mathrm{~m}$. In Case 3 , we installed one bar type groyne $135^{\circ}$ 
to the stream flow, at intervals of $1 \mathrm{~m}$. In Case 4, we installed double bar type groyne $135^{\circ}$ to the stream flow, at intervals of $1 \mathrm{~m}$. In Case 5 , we installed double bar type groyne $45^{\circ}$ to the stream flow, at intervals of $2 \mathrm{~m}$.

Table 1: Conditions for each case Table 2: Comparisons with install in straight and meander conditions of groynes. streams.

\begin{tabular}{|c|c|c|c|c|c|c|}
\hline \multicolumn{2}{|c|}{$\begin{array}{l}\text { Classifi } \\
\text {-cation }\end{array}$} & Case & $\begin{array}{c}\text { Case } \\
2\end{array}$ & $\begin{array}{c}\text { Case } \\
3\end{array}$ & $\begin{array}{c}\text { Case } \\
4\end{array}$ & $\begin{array}{c}\text { Case } \\
5\end{array}$ \\
\hline \multirow{3}{*}{ 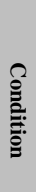 } & shape & & $\begin{array}{l}\text { one } \\
\text { bar }\end{array}$ & $\begin{array}{l}\text { one } \\
\text { bar }\end{array}$ & $\begin{array}{c}\text { double } \\
\text { bar }\end{array}$ & $\begin{array}{c}\text { double } \\
\text { bar }\end{array}$ \\
\hline & $\begin{array}{c}\text { interval } \\
(\mathrm{m})\end{array}$ & & 1 & 1 & 2 & 2 \\
\hline & $\begin{array}{c}\text { Angle } \\
(\theta)\end{array}$ & & $45^{\circ}$ & $135^{\circ}$ & $45^{\circ}$ & $45^{\circ}$ \\
\hline
\end{tabular}

\begin{tabular}{|c|c|c|c|c|c|}
\hline $\begin{array}{c}\text { Classifi } \\
\text {-cation }\end{array}$ & Case 1 & Case 2 & Case 3 & Case 4 & Case 5 \\
\hline Case 1 & & install & & & \\
\hline Case 2 & in s t a l l & & ang le & shape & \\
\hline Case 3 & & ang le & & & \\
\hline Case 4 & & shape & & & in terval \\
\hline Case 5 & & & & interval & \\
\hline
\end{tabular}

\subsubsection{Results}

(1) Case 1 (Not installation of groynes) VS Case (After installation of one bar type groyne)

The change of bed and edge of stream in Case 3 was more various than in Case 1. Deposition and erosion resulting from the one bar type groynes of Case 3 could be found and puddles were formed near the groynes. Bed erosion of the middle part of the meander stream in Case 3 contrary to Case 1 was increased $0.027 \mathrm{~m}^{3}$ in $1 \mathrm{Q}$ test and $0.0857 \mathrm{~m}^{3}$ in $2 \mathrm{Q}$ test. Because this results shows that Case 3 has more flow intensity than in Case 1.

(2) Case 2 (Installation angle: $45^{\circ}$ ) VS Case 3 (Installation angle: $135^{\circ}$ )

At upper, middle and lower parts of the straight stream, sectional soil deposition and erosion appeared inversely as being varied the installation angle. In 1Q experiment, more erosion was found in Case 3 than in Case 2. (upper part variation: $0.128 \mathrm{~m}^{3}$ ) In 2Q experiment, the variation of bed and edge in Case 2 $\left(45^{\circ}\right)$ were more diverse than in Case $3\left(135^{\circ}\right)$. It is expected that $135^{\circ}$ groynes can create in normal season more various bed and edge changing than flood season. At the rear side of groynes, the change of erosional forms was found in case of $45^{\circ}$ while depositional forms of $135^{\circ}$. Thus, it is indicated that the installation angle can be a highly major factor for the inducement of topographic change.

(3) Case 2 (groyne type: one bar) VS Case 4 (groyne type: double bar)

In the Case 4 was appeared erosion at the inside of double bar type groynes. Because the water flow occurred inside of double bar type groyne which was grown induced festination of particle velocities. For this reason, puddles were formed due to the inner erosion. In 1Q experiment, it was indicated that double bar type groynes were more effective in creating various bed and edge of the stream changes than one bar type groynes. In double bar type groynes after $2 \mathrm{Q}$ experiment, deposition and erosion forms were reversed due to the movement of 
soil. (Topographic variation between 1Q and 2Q: $0.1003 \mathrm{~m}^{3}$ (Case 2), $0.0162 \mathrm{~m}^{3}$ (Case 3)) In order to induce various topographic changes, double bar type groyne which can give variety to velocities is concluded to be more effective than one bar type groyne.

\begin{tabular}{|c|c|c|c|c|}
\hline $\begin{array}{l}\text { classif } \\
\text { ication }\end{array}$ & 1Q-base & 2Q-base & $2 Q-1 Q$ & Level \\
\hline Case 1 & 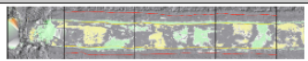 & 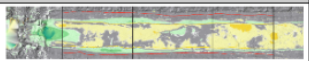 & 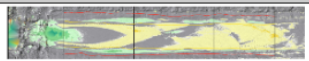 & \\
\hline Case 2 & 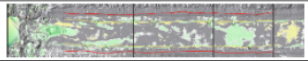 & 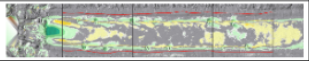 & 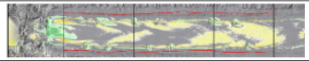 & \\
\hline Case 3 & 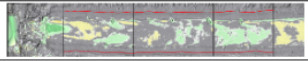 & 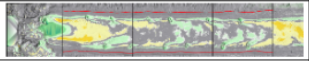 & 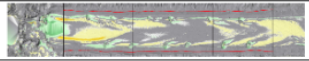 & \\
\hline Case 4 & 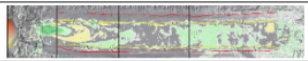 & Kons & 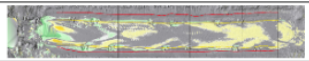 & \\
\hline Case 5 & 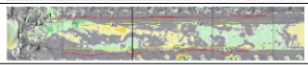 & 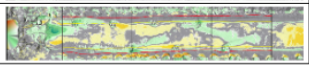 & 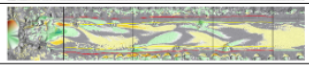 & \\
\hline
\end{tabular}

Figure 4: Bed displacements with each case in straight stream of experimental test bed.

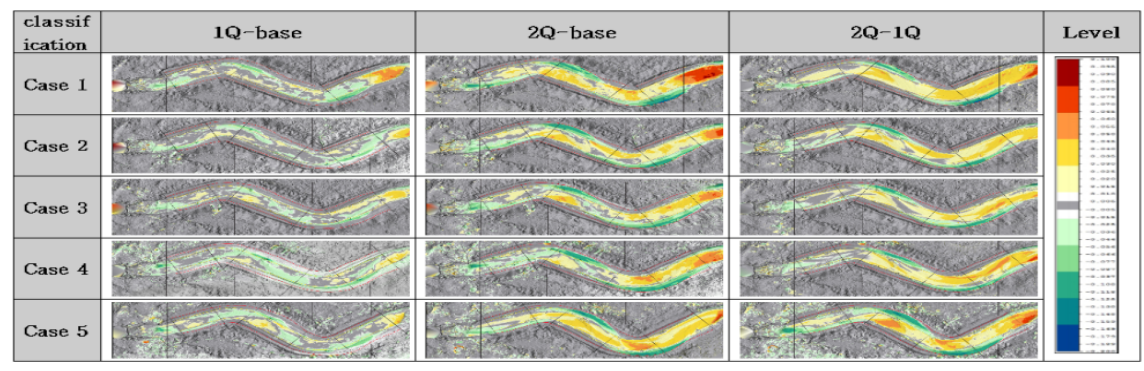

Figure 5: Bed displacements with each case in meander stream of experimental test bed.
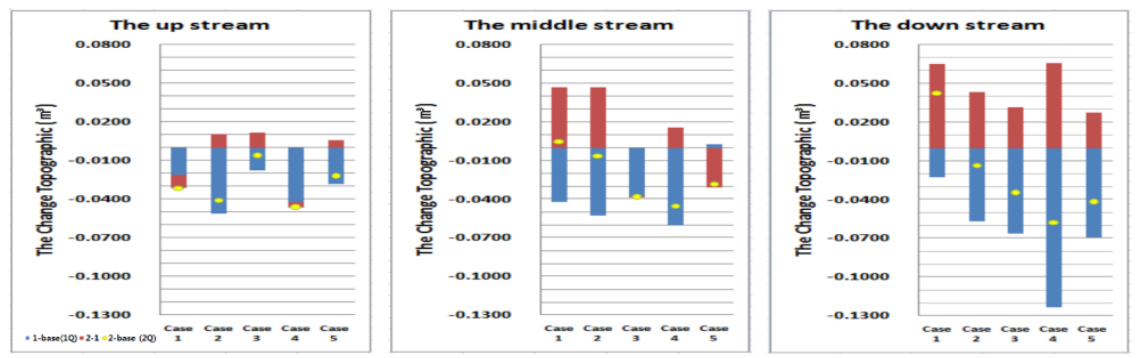

Figure 6: Changes of topographic mass $\left(\mathrm{m}^{3}\right)$ in straight stream of experimental test bed. 

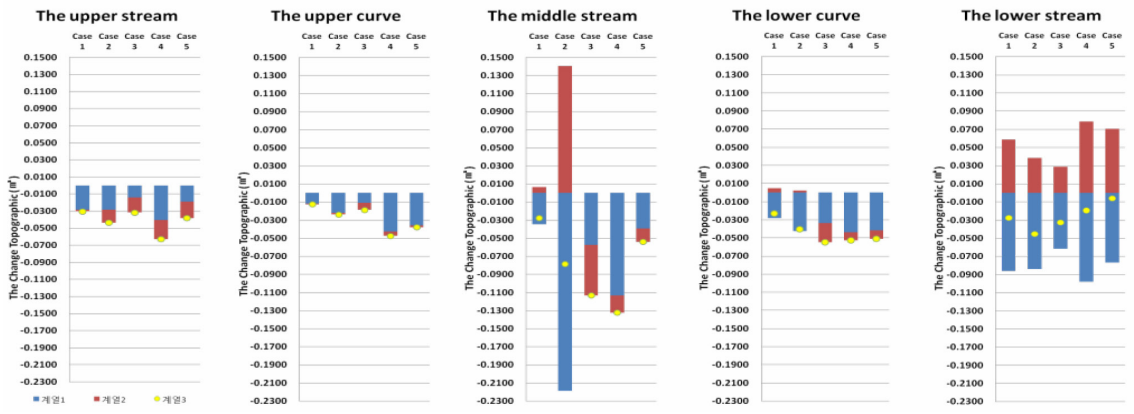

Figure 7: Changes of topographic mass $\left(\mathrm{m}^{3}\right)$ with each case in meander stream of experimental test bed.

At all cases and all sections of the straight stream without groynes, Case 1 had simple topographic changes and most of changes were erosion. In the other four cases, which is with groynes, the changes of bed and edge of stream were various due to the groynes. In order to induce the topographic change in real streams, the simple installation of groynes can creative vary the geographical features. Through the topographic changes, new habitat functions can be attained. Furthermore, if groynes installation condition changed with seasonal and regional characteristics, it would induce various topographic change and biodiversity.

At all cases and sections of the meander stream, without groynes, Case 1 had simple and overall form of topographic variation also. In the other four cases, which are with groynes, the changes of bed and edge of stream were more various moving or changing their width and depth. On the basis of the results, groynes can function as a prevention of bank erosion and waterside destruction. Also they can create new geographical features such as alluvial islands or oxbow lakes by being applied to real meander streams.

\section{Field applications}

\subsection{Geumdang valley in Pyeongchang river}

As a result of simulation data, we installed thirteen wooden groynes arranged in one bar and double bar types. The flow velocity of Pyeongchang River in flood season during the past 18 years was $2-3 \mathrm{~m} / \mathrm{s}$ and maximum mean flow velocity was $4.05 \mathrm{~m} / \mathrm{s}$. (Internal Hydrological Program (IHP) Exp. Watershed 1982 2000)

Each collection was performed at each sampling site in upstream and downstream of groynes of Pyeongchang River using a kick net (mesh size 5 x 5 $\mathrm{mm}$ ). The collected fishes were released immediately after onsite identification and counting of the individual number. Their classification system was arranged under Nelson [6] and then identification and classification were conducted under Kim and Park [7]. 


\subsubsection{Change shape appearance}

The original form of riverside was a slow grade in broad outlines. After one year of from the installation groynes, it can be found that the topography around the groynes transformed into generally complex curves due to deposition and erosion as a result of a topographical survey. In particular, wetland puddles were created at the rear of the groynes. This installation of groynes functioned as creator of fish and benthic invertebrate habitat, various changed riverside forms which were simple before.

To see more various topographic changes, we subdivided the contour interval by selecting groynes to upper, middle and lower part of the installation section. Groynes at St. 1 corresponding to upper part of the section were submerged in ordinary times. In studying the topographic changes after one year from the installation, there were erosion at the rear while deposition at the front. At St. 2 in the middle part of the stream, the contour lines were changed intricately, which were simple before. Puddles were formed by erosion between groynes. At St. 3 in the lower part, topographic changes were appeared most widely through all the sections. Also, other puddles resulting from deposition and erosion were formed at the rear.

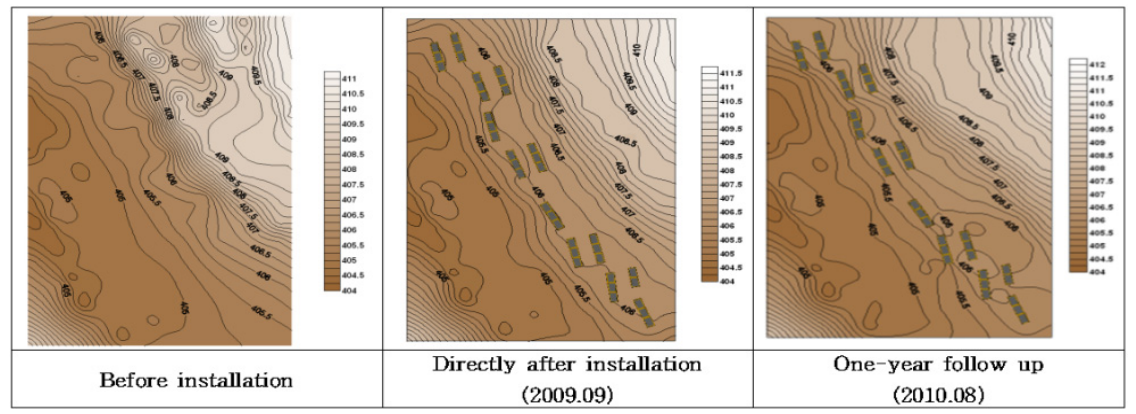

Figure 8: Contour maps of immediate and later installation of groynes in field test bed.

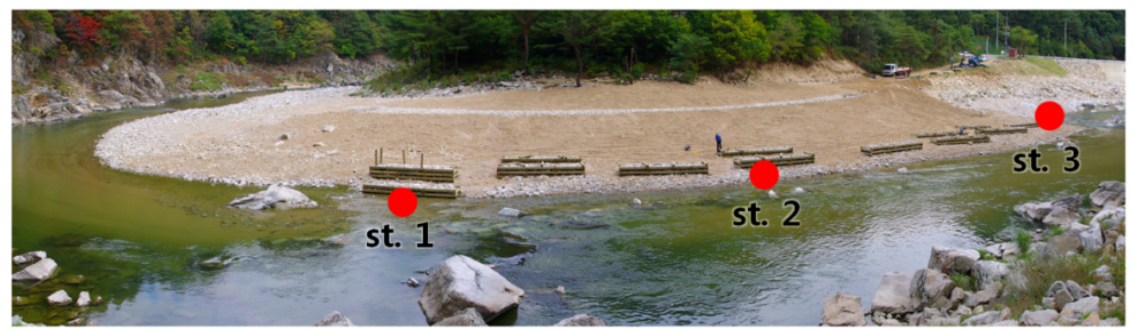

Figure 9: $\quad$ A picture of field test bed (Pyeongchang river). 


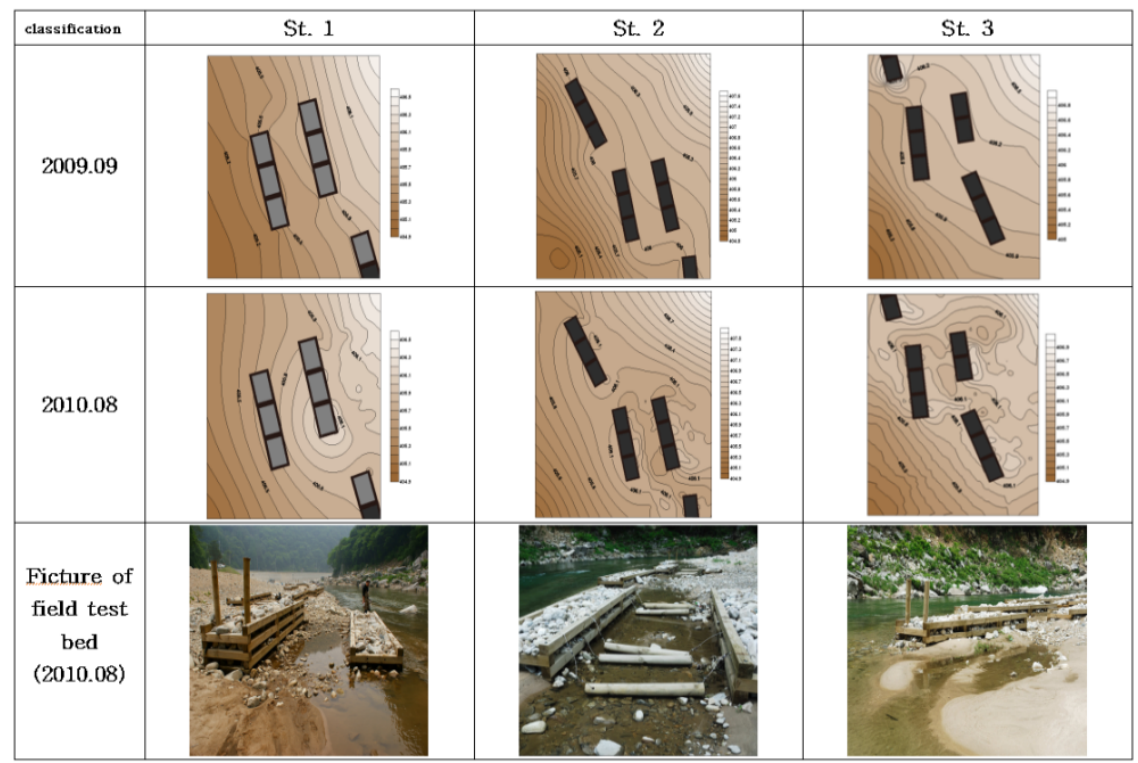

Figure 10: Partial contour maps and pictures in each part.

\subsubsection{Fish survey}

To evaluate the fish habitat created by groynes, It inquired into the ichthyofauna five times from 2009 when before installing the groynes until 2012 when after installing the groynes.

The collected species during the research were 3 orders 6 families 17 species 440 individuals. Before installing the groynes in 2009, one investigation was taken in September. Collected fishes were 3 families 7 species in total. In 2010 to 2012, after the installation, four investigations were conducted and collected fish were 6 families 14 species. After one year from installing the groynes, 8 species 43 individuals of fish were collected from the investigation in October, 2010. In November, 2011 investigation, after two years from the installation, 8 species 11 individuals of fish were collected. It did not seem to have a great change in species but Gobiobotia brevibarba and Koreocobitis rotundicaudata were added, which were not found in 2010. In 2012, two investigations were conducted in April and August. Collected fish were 5 families 12 species. In August, 2012 investigation, after three years from the installation, Hemibarbus mylodons, which is natural monument, were multiplied twelvefold in comparison with the amount before the installation. Also Pseudopungtungia tenuicorpa, which is second-level endangered species, were multiplied twentyfold.

In addition, Banarescu and Orthrias toni were found, which were not collected before. Also, the number of Zacco platypus and Zacco koreanus was increased. 


\subsubsection{Invertebrate survey}

The number of invertebrates in 2010 was a twofold increased comparing with in 2009 , before the installation of groynes. In 2010, after the installation, the density of rainfall was increased over a year ago. For this reason, various riverbed habitats were created near the groynes. So it can be judged as a factor of natural increment of invertebrates. Especially after the middle of May, the beginning of rainy season, we could find steep increases of species and individuals. General increases of species and individuals. It can be found out that overall increase of species in the field test area after the installation is more stable than before the installation. Besides, we checked habitat distribution of Family Perlodidae (Megarcys ochracea) which is katharobity indicator species. Various velocities were occurred resulting from the vortex near the groynes. In this reason, microhabitats were created changing the riverbed material. So it can be indicated that these reasons results the appearance of new species.

We focused that the upper part (St. 1) of groyne installation section functioned of erosion prevention and velocity reduction and the middle part (St. 2) functioned of creating riverbed habitats and lower part (St. 3) functioned of creating puddles as a role of wetland. In the upper part (St. 1), which was a erosion section in flood season, there was not any of the topographic erosion even after the flood season. In the overall installation sections, small scale topographic changes which can function as microhabitats were occurred near the groynes. Though the rapidly changing seasonal rate of flow, topographic changes have been well maintained. As a result, fish fauna change was occurred and individuals were increased. In every section of stream (St. 1, St. 2 and St. 3), faunas were also increased. After the installations, we could find the increment of faunas and individuals as well even after the flood season.
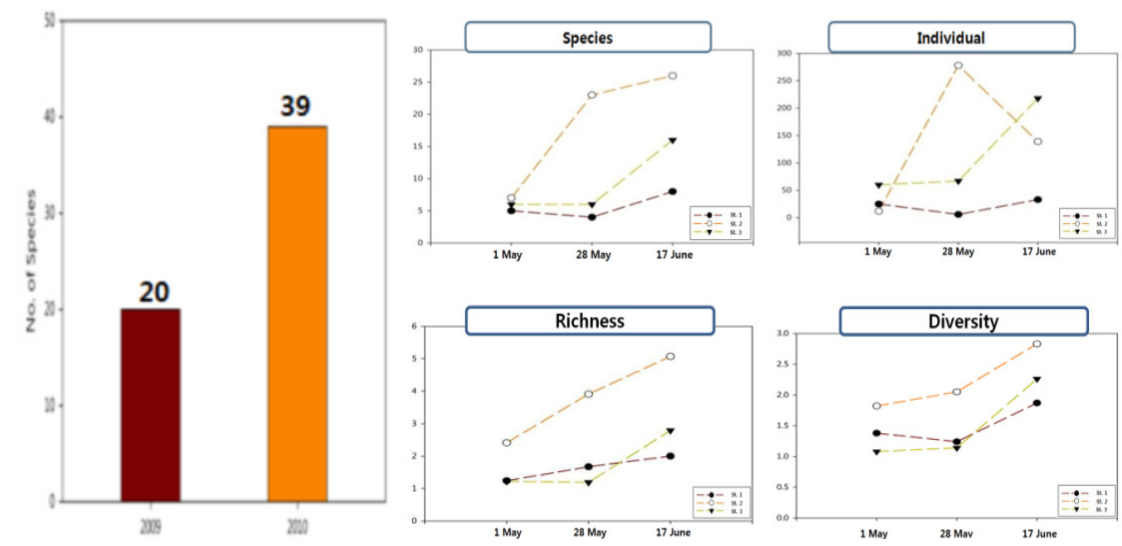

Figure 11: Changes of invertebrates before and after the installation of groynes. 


\section{Conclusion}

In this study, we observed topographic changes resulting from installed groynes at straight and meander experimental test-bed. After that we applied them to Field test bed to conduct a comparative analysis. Also, we observed the various topographic changes could form kinds of habitats of fishes and benthic invertebrates. The main contents from this study are shown below

Observation results of topographic changes caused by groynes at straight and meander experimental test bed (Shihwa Wetland)

i) Various bedform changes were induced with installation of groynes than without groynes.

ii) In comparison of the installation angle of groynes, erosion was found in case of $45^{\circ}$ to the stream flow while deposition in case of $135^{\circ}$. Installation angle can be used as a main factor in creating more various topographic changes.

iii) In comparison of the installation shape of groynes, various topographic changes were found more with double bar type groynes than one bar type groynes. It is considered that the velocity change of the inside of double bar type groyne can vary the deposition and erosion.

Observation results of topographic change and biogacies after more than one year from the installation of groynes at field test bed (Geumdang Valley) based on experimental test bed results.

i) After one year from the installation of groynes, various forms of puddles and sedimentary topography were found at the field test area which was considerably simple terrain. As a result of that, contour lines became greatly complex. In the real stream, which minimized man made elements, more forms of bed and edge of stream could be created only with the installation of groynes similar to the results of test-bed. Also the created spaces could function as various shelters or hideouts for aquatics.

ii) The fauna variation before and after the installation of groynes shows that Hemibarbus mylodon, which is natural monument, was multiplied twelvefold in comparison with the amount before the installation. Also Pseudopungtungia tenuicorpa, which is second-level endangered species, was multiplied twentyfold. In addition, Banarescu et Nalbant and Orthrias toni were found, which were not collected before. Also, the number of Zacco platypus and Zacco koreanus was increased.

iii) The number of invertebrates in 2010 was doubled comparing before the installation of groynes. Changing the riverbed material, microhabitats were created. Moreover, habitat distribution of Family Perlodidae (Megarcys 
ochracea), which is katharobity indicator species, shows that a stable web of life was built in and around the groynes.

\section{Acknowledgement}

We are grateful for research funding provided by Eco-STAR project of Korean Ministry of Environment.

\section{References}

[1] Mohamed F, M. Yossef and Huib j. de Vriend, Sediment exchange between a river and its groyne fields: Mobile-bed experiment. Journal of hydraulic engineering, pp. 610-611, 2010.

[2] J.G. Kang, H.K. Yeo, Experimental study on the flow characteristics of type groynes. Scientific research, pp. 1002-1011, 2011.

[3] Gard, R.J., Subramanya, K., Nambudripad, K.D., Study of scour around spur-dike. J. Hydraulic Eng. 87(HY6), 23-37, 1961.

[4] Gill, M.A., Erosion of sand beds around spur dikes. J. Hydraulic Eng. 98(HY9), 1587-1602, 1972.

[5] C.W. Byun, Eco-river, Namudosi: Korea, pp. 50-52, 2011.

[6] Nelson, J. S, Fishes of the world (3rd edition), John Wiley \& Sons, New York, 1994.

[7] I.S. Kim, J.Y. Park, Freshwater fishes of Korea, Kyohaksa, Korea, 2005. 